\title{
The Design and Check of Regional Typical Rainfall Processes: A Case Study of Yongnian District, China
}

\author{
Zihao Man ${ }^{1,2}$, Qinghua Luan ${ }^{1,3}$, Dan $\mathrm{Xu}^{1 *}$, Congwu Sun ${ }^{1,2}$, Yongzhen Niu ${ }^{1}$ \\ ${ }^{1}$ Hebei University of Engineering-College of Water Conservancy and Hydropower Engineering, Handan, China \\ ${ }^{2}$ Hebei Provincial Research Center of Water Ecological Civilization \&Social Governance, Handan, China \\ ${ }^{3}$ Research Center for Water Ecological Civilization \& Social Governance of Hebei Province, Handan, China
}

\begin{abstract}
Observing and analyzing runoff process is an important method to study the principle of runoff yield and concentration. However, natural rainfall is random and difficult to monitor the related runoff process timely, so most of the runoff processes analysis is based on the artificial rainfall experiments. In this study, the selected test site is located in Yongnian district, Hebei Province, China. Rainfall volume, rainfall peak, rainfall duration and peak ratio were considered as the key factors of designed rainfall type. Based on regional historical observed rainfall data from 1980 to 2012, the two mainly representative processes which was in flood season and non-flood season respectively, were calculated. The most typical rainfall process in each period was screened through two methods of characteristic frequency distribution. Furthermore, accuracy of rainfall intensity and uniformity of spatial and temporal distribution were selected as the criteria for correcting the artificial rainfall devices. This research is the foundation of the artificial runoff experiment and provide reference to regional climate change research and local water resources assessment.
\end{abstract}

\section{Introduction}

Water resources are the foundation of social development, it is crucial for crop growth, industrial production and lives. With the increasing urbanization, the demand for water resources increases ${ }^{[1]}$. Rainfall study is the foundation of hydrology and crucial for the research on runoff yield and concentration. The artificial rainfall process is chosen for most of experiment and research on runoff yield and concentration, because of the randomness of natural rainfall. Thus, the design of artificial rainfall is very significant. Most of the researches on design rainfall focus on designed rainstorm ${ }^{[2-5]}$ and the corresponding researches on the temporal and spatial variation of rainstorm ${ }^{[6-8]}$ and the design of rainstorm types ${ }^{[9-18]}$ have been rapidly developed, but these were emphasis on the damage influenced by the different rainfall types and ignored the runoff response of underlying surface influenced by normal rainfall. Another studies aimed to the principle of runoff yield and concentration on underlying surface ${ }^{[19-21]}$, and the corresponding rainfall process was designed according to the test requirements, which is lack of representativeness of regional rainfall characteristics, and unserviceability for the principle searching of runoff yield and concentration of normal rainfall in study area.

Hourly rainfall data from $1^{\text {st }}$ April to $31^{\text {st }}$ October in Yongnian district from 1980 to 2012 was collected. The key factors of design are four characteristics, which is rainfall quantity, rainfall peak, rainfall duration and peak ratio respectively. Mutual verification through two characteristic frequency distribution methods. Then, the typical representative rainfall in flood season and non flood season was designed respectively. It can greatly reflect the rainfall characteristics of flood season and nonflood season, and regional rainfall differences in different periods were analyzed, and the strong support for the study of runoff yield and concentration was provided. Meanwhile, taking the Linmingguan experimental site of Hebei University of Engineering as an example, accuracy of rainfall intensity and uniformity of precipitation in time and space were criteria for performing rainfall verification on artificial rainfall devices, actual artificial rainfall was checked, and solution was proposed. The research results can provide reliable guarantee for the next test.

\section{Materials and Methods}

\subsection{Study area}

Yongnian district is located in the northern part of Handan City, Hebei Province, $20 \mathrm{~km}$ from city center and $420 \mathrm{~km}$ from Beijing. Yongnian is located in the transition zone between the low hills and the North China Plain, and the terrain is decreasing from west to East. The landforms are mainly three types: hilly, plain and low-lying lakes. And it is located in semi-humid and semiarid region, and belongs to warm temperate continental monsoon climate. The winter is cold and dry, the spring is more wind and less rainy, the autumn is cool, and the summer is hot and rainy. The annual average precipitation is $527.8 \mathrm{~mm}$, and

\footnotetext{
*Corresponding author: Dan Xu,1161481144@qq.com.
} 
the precipitation is unevenly distributed during the year (about $60 \%$ of rain is in the flood season) and the annual variation is large. The annual average temperature is $14^{\circ} \mathrm{C}$, the coldest month (January) average temperature is $-2.5^{\circ} \mathrm{C}$, the extreme minimum temperature is $-20^{\circ} \mathrm{C}$, the hottest month (July) average temperature is $27^{\circ} \mathrm{C}$, and the extreme maximum temperature is $42.5^{\circ} \mathrm{C}$. The annual frostless period is 200 days, and the annual sunshine is $2557 \mathrm{~h}$.

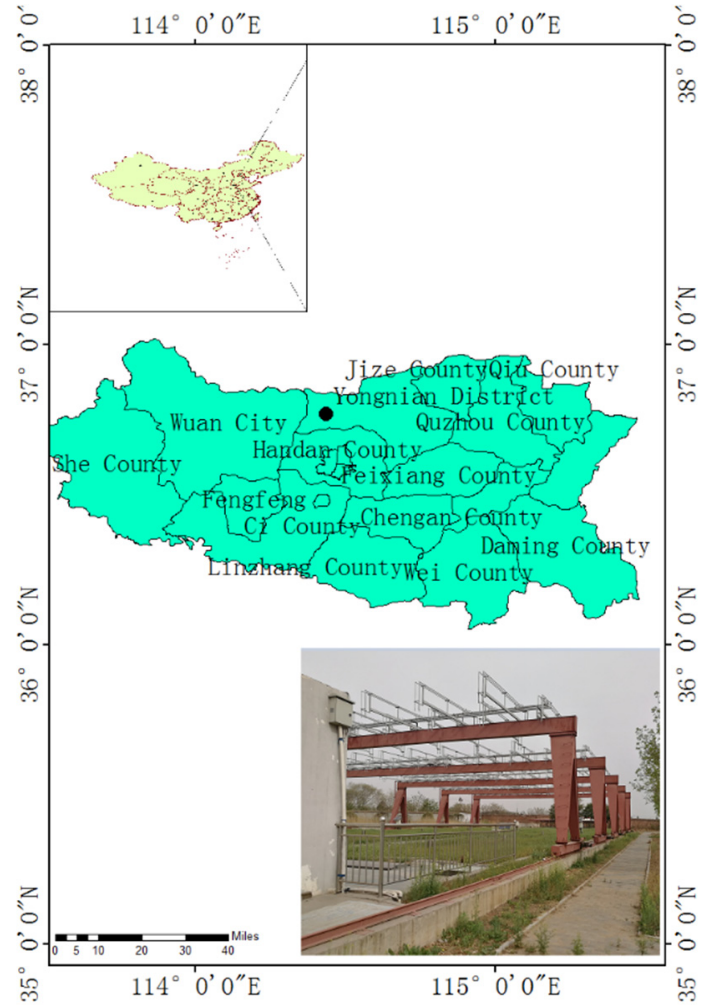

Figure 1. Experimental site is located in Yongnian District, Hebei Province, China.

\subsection{Measurements and data}

The rainfall data in this research was collected from the "Hourly precipitation datasets for national meteorological stations in China (V1.0) ". And the data are hourly rainfall data from April 1st to October 31st in Yongnian district for 1980-2012 years, which has been checked. Each group of data has a quality control code and the source is reliable. Rainfall data in each group begins at 20-21 hours and ends at 19-20 hours on the next day, and the unit is $0.1 \mathrm{~mm}$. Because of the data is huge, so according to the characteristics of regional runoff yield and concentration, a rainfall process of rainfall quantity more than $10 \mathrm{~mm}$ was selected to design typical rainfall.

Because the rainfall in the region is mostly concentrated in the flood season from June to September ${ }^{[22-24]}$ ( The main flood season is from July to August.), and the rainfall type in the flood season is different from the non-flood season. Therefore, rainfall data was divided into flood season data and non-flood season data. The typical rainfall in different periods is calculated separately to ensure that the rainfall characteristics can be reflected to the greatest extent and provide accurate and reliable rainfall process for the study of runoff yield and concentration.

\subsection{Typical rainfall design based on the method of characteristic frequency distribution}

\subsubsection{The rainfall quantity was used as a variable to calculate the rainfall type}

First, according to the rainfall level, the rainfall quantity is divided into 6 levels of $0-10 \mathrm{~mm}, 10-25 \mathrm{~mm}, 25-50 \mathrm{~mm}$, $50-100 \mathrm{~mm}, 100-250 \mathrm{~mm}$, and above $250 \mathrm{~mm}$, the rainfall quantity of all the rainfalls is sorted out and counted. The rainfall quantity is used as a variable to arrange frequency, and all rainfalls corresponding to the highest frequency of rainfall level are selected (As sample 1), and the rainfall quantity in sample 1 is averaged, the average rainfall quantity is the rainfall quantity of typical rainfall. Then, the rainfalls arrangement frequency in sample 1 is determined by rainfall peak and rainfall duration (Among them, the rainfall peak is 1 level per $1 \mathrm{~mm}$, and the rainfall duration is 1 level per $1 \mathrm{~h}$.), the rainfall peak level with the highest frequency of occurrence is averaged, the average rainfall peak is the rainfall peak of typical rainfall, and the rainfall duration with the highest frequency of occurrence is the rainfall duration of the typical rainfall. Next, from the sample 1, we screen out the corresponding rainfalls with the highest frequency of rainfall duration (As sample 2 ), the rainfalls arrangement frequency in sample 2 is determined by simple peak ratio, the simple peak ratio with the highest frequency of occurrence is the peak ratio of the typical rainfall. The peak ratio is calculated as follows:

$$
R=\frac{t_{i}}{T}
$$

where $t_{i}$ is rainfall peak time, $T$ is rainfall duration. The peak ratio can specifically reflect the time of peak occurrence, and the rainfall process is described better.

Based on the seven rainfall types proposed by the Cen Guoping ${ }^{[25]}$, this research summarizes six simple peak ratios in combination with the design rainfall requirement (Figure 2): 1- Single peak and anterior part, 2- Single peak and central section、3- Single peak and posterior part, 4Single peak and larger anterior part, 5-double peak and same size, 6-double peak and larger posterior part. 

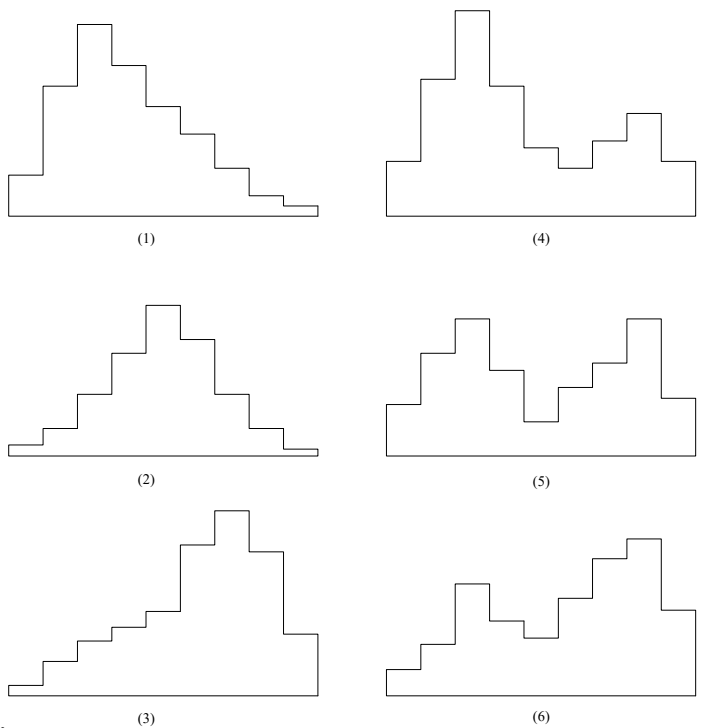

Figure 2. The schematic diagram of simple peak ratio

The rainfall quantity, rainfall peak, rainfall duration and peak ratio of typical rainfall can be obtained by the above methods. A typical rainfall process can be designed from these eigenvalues.

\subsubsection{The rainfall duration was used as a variable to calculate the rainfall type}

First, the rainfall duration of all the rainfalls is sorted out and counted, the rainfall duration is used as a variable to arrange frequency, the rainfall duration with the highest frequency of occurrence is the rainfall duration of the typical rainfall, and we screen out the corresponding rainfalls with the highest frequency of rainfall duration (As sample 3). Then, the rainfalls arrangement frequency in sample 3 is determined by rainfall quantity and simple peak ratio, the rainfall quantity level with the highest frequency of occurrence is averaged, the average rainfall quantity is the rainfall quantity of typical rainfall, and the simple peak ratio with the highest frequency of occurrence is the simple peak ratio of typical rainfall. Next, from the sample 3, we screen out the corresponding rainfalls with the highest frequency of rainfall quantity (As sample 4), the rainfalls arrangement frequency in sample 4 is determined by rainfall peak, the rainfall peak level with the highest frequency of occurrence is averaged, the average rainfall peak is the rainfall peak of typical rainfall. Finally, a typical rainfall process can be designed from the rainfall quantity, the rainfall peak, the rainfall duration and the peak ratio.

\subsubsection{The method of calculate typical rainfall}

On the basis of the typical rainfall eigenvalues calculated by the two characteristic frequency distribution methods, the eigenvalues are compared and analyzed. If the obtained eigenvalues are the same, it is the typical rainfall eigenvalue. Otherwise, in all the rainfalls, the characteristic of the difference is used as a variable to arrange frequency, the eigenvalue with the highest frequency of occurrence is the reference. The eigenvalue closest to the reference is the typical rainfall eigenvalue. The frame of a typical rainfall process is constructed by typical rainfall duration, typical rainfall peak, and typical rainfall simple peak ratio. Then, except for the peak, other periods of rainfall quantity are filled through the typical rainfall quantity. Finally, the typical rainfall process is obtained. The flow chart for designing typical rainfall is shown in Figure 3.

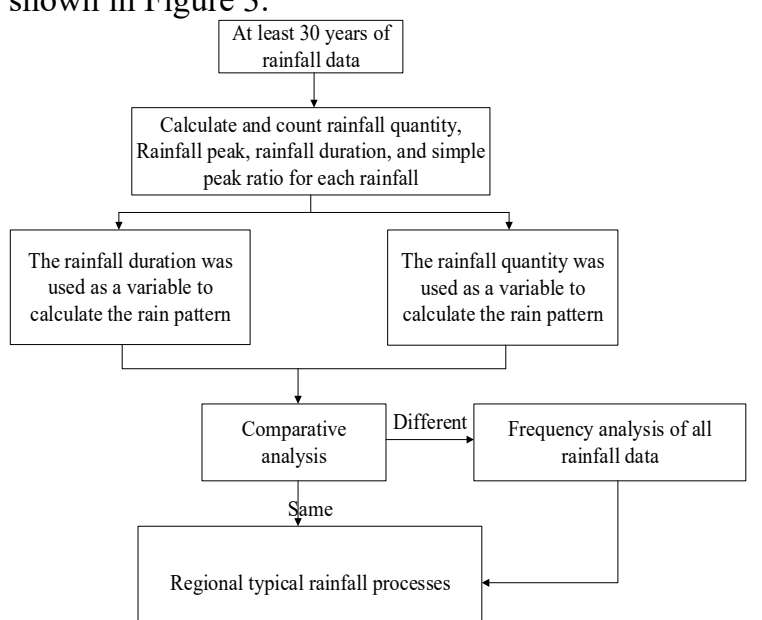

Figure 3. The process diagram of calculate typical rainfall

For a rainfall process, rainfall quantity is closely related to rainfall duration, rainfall peak is closely related to rainfall quantity, and simple peak ratio is closely related to rainfall duration. So rainfall quantity and rainfall duration are used as primary variable respectively. From two different starting points, the typical rainfall eigenvalues are derived according to the correlation size, and typical rainfall eigenvalues are compared and analyzed to make the result more accurate and relevant, and the regional rainfall characteristics are better reflected.

\section{Typical rainfall in flood season and non-flood season}

\subsection{Typical rainfall in flood season}

Based on the rainfall data of 33 years in flood season, the characteristic frequency distribution method is used to calculate the typical rainfall during the flood season by using the rainfall quantity and rainfall duration as the variables, the result is shown in Table 1. From table 1, the rainfall quantity and rainfall peak of typical rainfall in flood season are basically the same, the differences are mainly reflected in rainfall duration and simple peak ratio. Because the simple peak ratio is calculated on the basis of the typical rainfall duration, it is only necessary to analyze the rainfall duration through all the rainfall data in flood seasons.

Table 1. The rainfall duration and rainfall quantity were used as variables to calculate the typical rainfall processes in flood

\begin{tabular}{|c|c|c|c|c|}
\hline & $\begin{array}{c}\text { Rainfall } \\
(\mathbf{m m})\end{array}$ & $\begin{array}{c}\text { Rainfall } \\
\text { peak } \\
\mathbf{( m m})\end{array}$ & $\begin{array}{c}\text { Rainfall } \\
\text { duration } \\
\text { (h) }\end{array}$ & $\begin{array}{c}\text { Simple } \\
\text { peak } \\
\text { ratio }\end{array}$ \\
\hline $\begin{array}{c}\text { Taking } \\
\text { rainfall } \\
\text { quantity as } \\
\text { variable }\end{array}$ & 17.2 & 13.4 & 2 & $\begin{array}{c}\text { Single } \\
\text { peak } \\
\text { and }\end{array}$ \\
\hline
\end{tabular}




\begin{tabular}{|c|c|c|c|c|}
$\begin{array}{c}\text { arrangement } \\
\text { frequency }\end{array}$ & 17 & 3.5 & 3 & $\begin{array}{c}\text { anterior } \\
\text { part }\end{array}$ \\
\hline $\begin{array}{c}\text { Taking } \\
\text { rainfall } \\
\text { duration as } \\
\text { variable } \\
\text { arrangement } \\
\text { frequency }\end{array}$ & 17 & $\begin{array}{c}\text { Single } \\
\text { peak } \\
\text { and } \\
\text { central } \\
\text { section }\end{array}$ \\
\hline $\begin{array}{c}\text { Typical } \\
\text { rainfall in } \\
\text { flood } \\
\text { season }\end{array}$ & 17.1 & 13 & 3 & $\begin{array}{c}\text { Single } \\
\text { peak } \\
\text { and } \\
\text { central } \\
\text { section }\end{array}$ \\
\hline
\end{tabular}

There were a total of 251 rainfall data during the flood season, in which rainfall duration for 3 hours with the highest frequency, rainfall duration for 4 hours is second place. So, the typical rainfall duration is $3 \mathrm{~h}$, which is more representative than that of 2 hours, and the simple peak ratio is single peak and central section. Because the rainfall quantity and rainfall peak of typical rainfall in flood season calculated by the two characteristic frequency distribution methods are basically the same, the average is the rainfall quantity and rainfall peak of typical rainfall in flood season, the result is shown in Table 1 . The frame of the typical rainfall process in flood season is constructed through four eigenvalues, and except for the peak, other periods of rainfall quantity are filled through the typical rainfall quantity. In the large amount of rainfall dates during flood season, the single peak and central section of rainfall in the first half of the rainfall quantity is slightly larger than that in the latter half. So, we can get the typical rainfall process in the flood season shown in Figure 4.

From the typical rainfall process in flood season, we can see that the characteristics of rainfall in flood season are mostly short and urgent. Although the rainstorm will increase relatively in flood season, the representativeness is low, which does not reflect the impact of most of the rainfall in flood season on the principle of runoff yield and concentration.

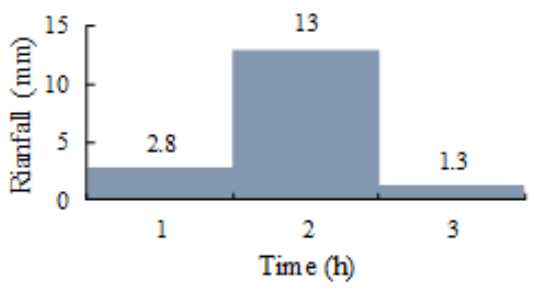

\subsection{Typical rainfall in non-flood season}

Based on the rainfall data of 33 years in non-flood season, the characteristic frequency distribution method is used to calculate the typical rainfall during the non-flood season by using the rainfall quantity and rainfall duration as the variables, the result is shown in Table 2. From Table 2, the rainfall duration and simple peak ratio of typical rainfall in non-flood period are completely consistent, and the rainfall quantity and rainfall peak of typical rainfall in non-flood season are basically the same. So the rainfall eigenvalues in non-flood season need not be corrected. The rainfall quantity and rainfall peak calculated by the two characteristic frequency distribution methods are averaged to obtain the four eigenvalues of the typical rainfall during the non-flood season (Table 2). The frame of the typical rainfall process in non-flood season is constructed through four eigenvalues, and except for the peak, other periods of rainfall quantity are filled through the typical rainfall quantity. In the large amount of rainfall dates during non-flood season, the single peak and central section of rainfall in the first half of the rainfall quantity is obviously smaller than that in the latter half. So, we can get the typical rainfall process in the non-flood season shown in Figure 5 .

It can be seen from the comparison of the typical rainfall processes in the flood season and the non-flood season that the rainfall quantity in the flood season is relatively large, the rainfall process is short and urgent, the rainfall quantity in the non-flood season is relatively small, and the rainfall process is long and slow. These are accord with the characteristics of rainfall in flood season and non-flood season. And as far as the single peak and central section of rainfall is concerned, the rainfall quantity in flood season is mostly concentrated in the middle and front parts, while the rainfall quantity in nonflood season is relatively backward, it further reflects the characteristics of rainfall in different periods.

Figure 4. Typical rainfall processes in flood season

Table 2. The rainfall duration and rainfall quantity were used as variables to calculate the typical rainfall processes in non-flood season

\begin{tabular}{|c|c|c|c|c|}
\hline & $\begin{array}{c}\text { Rainfall } \\
(\mathbf{m m})\end{array}$ & $\begin{array}{c}\text { Rainfall } \\
\text { peak (mm) }\end{array}$ & $\begin{array}{c}\text { Rainfall } \\
\text { duration (h) }\end{array}$ & $\begin{array}{c}\text { Simple peak } \\
\text { ratio }\end{array}$ \\
\hline $\begin{array}{c}\text { Taking rainfall quantity as } \\
\text { variable arrangement frequency }\end{array}$ & 12.5 & 2.9 & 10 & $\begin{array}{c}\text { Single peak and } \\
\text { central section }\end{array}$ \\
\hline
\end{tabular}




\begin{tabular}{|c|c|c|c|c|} 
& & & & \\
\hline $\begin{array}{c}\text { Taking rainfall duration as } \\
\text { variable arrangement frequency }\end{array}$ & 12.75 & 2.75 & 10 & $\begin{array}{c}\text { Single peak and } \\
\text { central section }\end{array}$ \\
\hline Typical rainfall in flood season & 12.6 & 2.8 & 10 & $\begin{array}{c}\text { Single peak and } \\
\text { central section }\end{array}$ \\
\hline
\end{tabular}

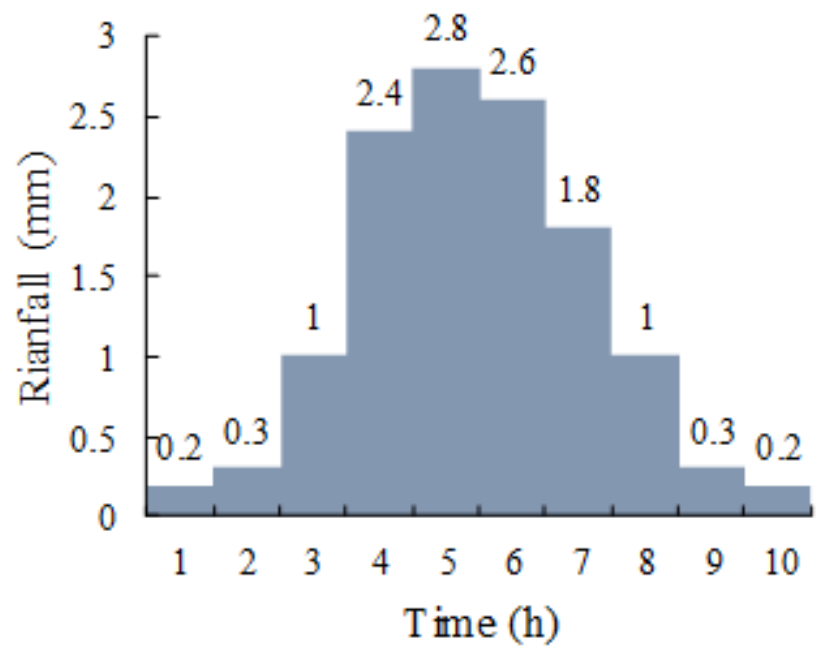

Figure 5. Typical rainfall processes in flood season

\section{Rainfall check}

\subsection{Check method}

Taking the Linmingguan experimental site (Experimental site for short, location is shown in Figure 1.) of Hebei University of Engineering as an example, there are three types of rainfall nozzle for artificial rainfall: small nozzle, middle nozzle and big nozzle. The types and quantities of nozzles and the degree of valve opening are controlled by the control system of artificial rainfall device to adjust the size of rainfall, as shown in Figure 6. Accuracy of rainfall intensity and uniformity of precipitation in time and space were criteria for performing rainfall verification on artificial rainfall devices, and the relationship between the control system of artificial rainfall device and the rainfall intensity and rainfall distribution will be determined and registered. The specific check methods are as follows ${ }^{[26]}$ :

(1) The accuracy of the rainfall intensity(Expressed by $R$ ) is measured by the ratio between the measured and setting rainfall intensity and the setting rain intensity. The smaller the value of $R$, the higher the accuracy, and the measured rainfall intensity is the arithmetic mean of the rainfall intensity at $\mathrm{n}$ points. The formula is as follows:

$$
\bar{P}=\frac{\sum_{i=1}^{n} P_{i}}{n}
$$

$$
R=\frac{\left|\frac{\bar{P}}{T}-Q_{\text {设 }}\right|}{Q_{\text {设 }}}
$$

where $P_{i}$ is rainfall quantity at each point, the unit is $\mathrm{mm}$. $Q$ is setting rainfall intensity, the unit is $\mathrm{mm} / \mathrm{h}$.

(2) The spatial distribution uniformity of rainfall is measured by the value of $k$. The larger the value of $k$, the spatial distribution of rainfall is more uniform. A value of $k$ equals 1 to indicate that the rainfall is completely uniform. The formula is as follows (The variables in the formula are the same as above):

$$
k=1-\frac{\sum_{i=1}^{n}\left|P_{i}-\bar{P}\right|}{n \bar{P}}
$$

(3) The temporal distribution of rainfall is analyzed by the plot of rainfall intensity over time. The temporal distribution of simulated rainfall in this experimental site will be analyzed by the trend of rainfall intensity in each period of rainfall process. 


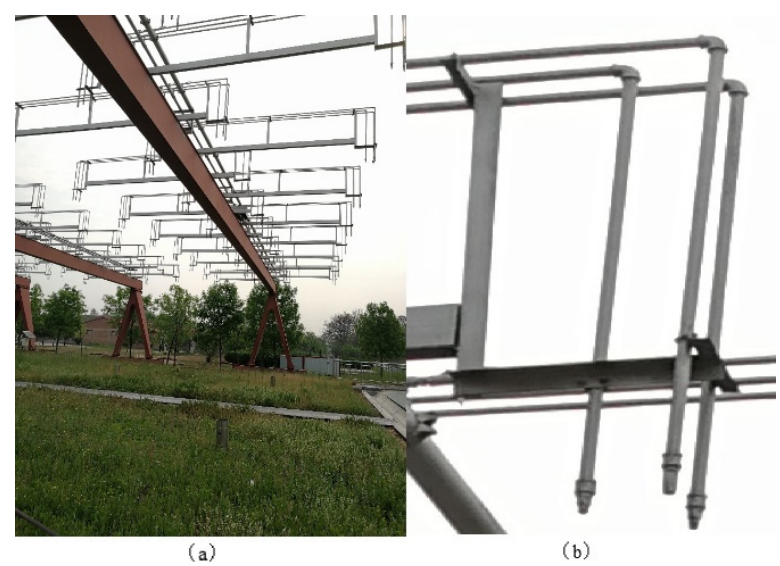

Figure 6. The schematic diagram of Experimental site(a) and nozzle(b)

\subsection{Results and analysis and discussion}

In this experiment, the four nozzle combinations of the artificial rainfall device in the experiment site are checked. From Table 3, when the three types of large, middle and small nozzles are in single-open mode, the value of $\mathrm{R}$ is greater than 0.5 , and the accuracy of rainfall intensity is poor. When the small nozzle and the middle nozzle are in double-open mode, the value of $\mathrm{R}$ is 0.08 , the accuracy of rainfall intensity is very well. This mode meets all kinds of experimental requirements, and can be considered in the runoff yield and concentration test. And the calibration result of spatial distribution uniformity of rainfall is well. Except for the middle nozzle, the other combinations of $\mathrm{k}$ are basically higher than 0.85 , the distribution of rainfall in each area is uniform.

From the results, the spatial distribution uniformity of artificial rainfall is very good in the experimental site, which can meet the test requirements. But in single-open mode, the test error of rainfall intensity is large, and the accuracy of rainfall intensity needs to be improved. However, when the small nozzle and the middle nozzle are in double-open mode, the accuracy of rainfall intensity is very well, it can greatly reduce systematic errors.

When designing the nozzle, the mist droplets are ejected through the nozzle to meet the natural rainfall characteristics. The raindrop is small in weight and far away from the ground, so there will be different degrees of migration under different wind forces in the process of rainfall calibration test, the interference of calibration results is obvious. In other words, besides the error of the instrument itself, the influence of wind force on the test results is also obvious. So the selection of suitable weather is very important to the test, and the interference of external factors is reduced as far as possible.

Table 3. The check result of accuracy of rainfall intensity and uniformity of precipitation in time and space

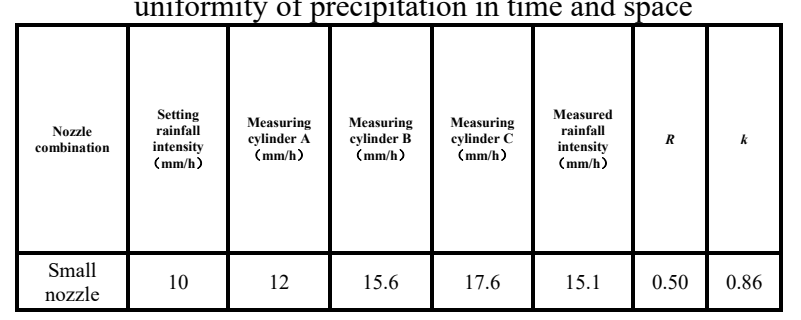

\begin{tabular}{|c|c|c|c|c|c|c|c|} 
& & & & & & & \\
\hline $\begin{array}{c}\text { Middle } \\
\text { nozzle }\end{array}$ & 30 & 56.1 & 51.3 & 52.3 & 53.2 & 0.77 & 0.64 \\
\hline $\begin{array}{c}\text { Big } \\
\text { nozzle }\end{array}$ & 60 & 109.3 & 103.5 & 96.2 & 103 & 0.72 & 0.96 \\
\hline $\begin{array}{c}\text { Small } \\
\text { and } \\
\begin{array}{c}\text { Middle } \\
\text { nozzle }\end{array}\end{array}$ & 60 & 59.5 & 70.2 & 64 & 64.6 & 0.08 & 0.94 \\
\hline
\end{tabular}

The temporal distribution uniformity of rainfall is checked by the curve of the proposed rainfall intensity over time. From Figure 7, the rainfall intensity experienced three stages during the entire artificial rainfall process: prophase descent stage(PDS), middle stable stage(MSS) and late descent stage(LDS). Rainfall intensity is uneven in time during the rainfall process, it appears as an obvious S-shaped curve. This phenomenon is related to the pump pressure inside the artificial rainfall device, and this factor needs to be considered by later tests.
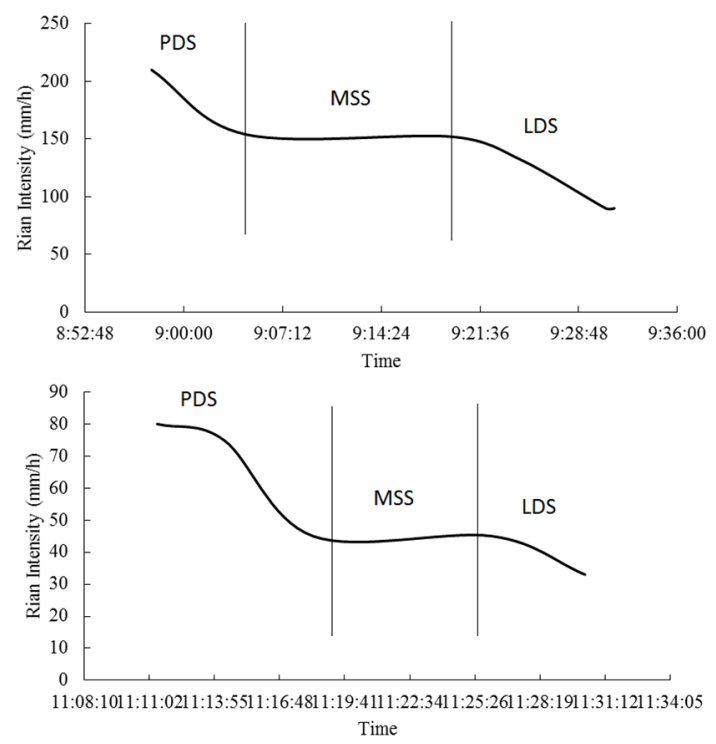

Figure 7. The change of rainfall intensity over time

As shown in Figure 7, there is an obvious "three stage" phenomenon in the entire artificial rainfall process. Because of the difference in rainfall intensity and rainfall duration, the cumulative rainfall quantity in the process of rainfall is also different, and the average rainfall intensity in the period will change accordingly. So the average rainfall intensity in unit time interval can be calculated by the quadrature of the curve of the proposed rainfall intensity over time. The period of typical rainfall process is divided by hours. So the variation of rainfall intensity with time under different setting rainfall intensity is proposed to pass the test, the first 1 hour of the curve is selected to obtain quadrature, the average rainfall intensity during the period is calculated, and the correspondence table between the setting rainfall intensity and the average rainfall intensity of the preceding 1 hour can be drafted. The relationship curve between the average rainfall intensity of the preceding 1 hour and the setting rainfall intensity can be drawn through the correspondence table. The setting rainfall intensity corresponding to the rainfall intensity at each period of the 
typical rainfall process can be read from the curve, and the rainfall intensity accuracy of the artificial rainfall device will be improved, and the test requirements will be satisfied.

\section{Conclusions}

Hourly rainfall data from April 1st to October 31st in Yongnian district for 1980-2012 years was the basis, the typical rainfall process in flood season and non-flood season is calculated through the characteristic frequency distribution method. And the accuracy of rainfall intensity and uniformity of rainfall precipitation in time and space are checked by the artificial rainfall device of Linmingguan experimental site. The conclusion is as follows:

(1) The characteristics of rainfall in flood season are mostly short and urgent, and the rainfall quantity is mostly concentrated in the middle and front parts. The eigenvalues in flood season are as follows: rainfall quantity is $17.1 \mathrm{~mm}$, rainfall peak is $13 \mathrm{~mm}$, rainfall duration is $3 \mathrm{~h}$ and simple peak ratio is single peak and central section. Although the rainstorm will increase relatively in flood season, the representativeness is low, which does not reflect the impact of most of the rainfall in flood season on the principle of runoff yield and concentration.

(2) The characteristics of rainfall in non-flood season are mostly long and slow, and the rainfall quantity is mostly concentrated in the middle and posterior parts. The eigenvalues in non-flood season are as follows: rainfall quantity is $12.6 \mathrm{~mm}$, rainfall peak is $2.8 \mathrm{~m}$, rainfall duration is $10 \mathrm{~h}$ and simple peak ratio is single peak and central section. The rainfalls in non-flood season is less, and the rainfall duration of non-flood season is long. In non-flood season, the underlying surface will be in a different state with seasonal changes, and the principle of runoff yield and concentration will also be different.

(3) When the small nozzle and the middle nozzle are in double-open mode, the error is the minimum, so the mode will be selected preferential in next experiments. Due to the influence of wind force, the error of singleopen mode is larger. It is suggested that weather factors should be considered in the test. And from the study of the change of setting rainfall intensity over time, a relationship curve between the average rainfall intensity of the preceding 1 hour and the setting rainfall intensity can be drawn to improve the accuracy of rainfall intensity.

The typical rainfall of each period has different characteristics, and the principles of runoff yield and concentration are also different. The results can provide strong support for the runoff yield and concentration experiments. In this paper, runoff yield and concentration is the primary conditions for designing typical rainfall, so rainfall quantity below $10 \mathrm{~mm}$ is not considered. However, the characteristic frequency distribution method can also be applied to other studies. The different requirements of rainfall can be designed through different primary conditions.

\section{Acknowledgement}

The researchers would like to extend their thanks to the National Natural Science Foundation of China (grant No. $51409078 \&$ 5 51879066) and the Natural Science Foundation of Hebei Province, China (No. E2017402178)

\section{References}

1. LIN George, CHU Sheng. Changing theoretical perspective on urbanization in Asian developing countries [J]. International Journal of Water Resources Development, 1991, 7(4):219-224.

2. X. Yang, DD. Zhu, CF. Li, ZL. Liu. Design rainfall pattern analyzed by risk rate model $[\mathrm{J}]$. Journal of Hydraulic Engineering,2013, 44(05):542-548.

3. M. Wang, XC. Tan. Study on urban rainstorm and rain Pattern in Beijing [J]. Hydrology, 1994(03):1$6+64$.

4. ZF. Zhuang, KQ. Wang, J. Yang, B. Chen, HT. Zhu. Development of a new generation of storm intensity formula and rain pattern design in Zhenjiang City [J]. Journal of the Meteorological Sciences, 2015,35(04):506-513.

5. ZY. Li, XJ. Huang, YY. He. Study on the method of designing rainstorm pattern $[\mathrm{J}]$. Municipal Engineering Technology, 2018, 36(01):141-143+150.

6. Kamran H S, David C G, Donald E M, et al. Spatial characteristics of thunderstorm rainfall fields and their relation to runoff $[\mathrm{J}]$. Journal of Hydrology, 2003, 271: 1-21.

7. Pechlivanidis I G, Mcintyre N R, Wheater H S, et al. Relation of spatial rainfall characteristics to runoff: Ananalysis of observed data [J]. Pro BHS National Hydrology Conference, University of Exeter, 2008(9): 86-94.

8. Neil McIntyre, Aisha AI-Qurashi, Howard Wherter. Regression analysis of rainfall-runoff data from an aridcatchment in Oman[J]. Hydrological Sciences Journal, 2007, 52(6): 1103-1118.

9. Keifer G J, Chu H H. Synthetic storm pattern for drainage design [J]. Journal of the Hydraulics Division, ASCE, 1957, 83(4): 1-25.

10. Huff $F$ A. Time distribution of rainfall in heavy storms [J]. Water Resources Research, 1967, 3(4): 1007-1019.

11. Pilgrim D H, Cordery I. Rainfall temporal patterns for design floods [J]. Journal of the Hydraulics Division, ASCE, 1975, 101(1): 81-95.

12. Yen B C , Chow V T . Design hyetographs for small drainage structures [J]. Journal of the Hydraulics Division, ASCE, 1980, 106 (6): 1055-1076.

13. Soil Conservation Service, USDA. Technical Release 55: Urban hydrology for small watersheds [R]. Washing-ton, D.C.: USDA, 1986.

14. JJ. Ma, LL. Song, XJ. Zhang. A comparative study on the Pilgrim \& Cordery rain patterns of two 
different sampling methods [J]. Torrential Rain and Disasters, 2016, 35(03):220-226.

15. J. Ning. Study on the short-term rainstorm intensity formula and design rain pattern in Shanghai [D]. Shanghai: Tongji University, 2006.

16. GP. Cen, Comparison of design rain patterns for urban rainwater storage pool calculation [J]. Journal of water resources and water engineering, 1993,4(2):30-41.

17. M. Jiang, Study on the design rainstorm pattern in Shanghai under the new situation $[\mathrm{J}]$. Journal of Hunan Institute of Science and Technology, 2015, 28(2):69.

18. LKF. Mo M B, et al. Rainwater channel and confluence channel [M].Beijing: China Architecture \& Building Press, 1956, 17-19.

19. H. Wu. Analysis of rainfall characteristics and experimental study on runoff yield and concentration characteristics of urban underlying surface in Xi'an [D]. Xi'an University of Technology, 2004.

20. PL. Gao, TW. Lei, MA. Shao, J. Zhao, C, et al. Experimental application of automatic measurement system for soil erosion and runoff process in small watershed [J]. Transactions of the Chinese Society of Agricultural Engineering, 2005(10):164-166.

21. LQ. Qu, TW. Lei, J. Zhao, XX. Yu, PL. Gao. Experiment on rainfall production process in indoor small watershed $[\mathrm{J}]$. Transactions of the Chinese Society of Agricultural Engineering, 2008, 24(12):25-30.

22. XL. Wang, M. Yang. Analysis of precipitation and weather system in flood season in Haihe River Basin in 2002 [J]. Haihe Water Resources, 2004(01):26-27.

23. ZL. Xu, Y. Cao, M. Yang. Temporal and Spatial Variation Characteristics of Precipitation in the Flood Season of the Haihe River Basin from 1951 to 2005 [J]. Hydrology, 2009, 29(01):85-88+82.

24. L. Wei, Z. Xu, ZQ. Zhang. Multi-scale analysis and prediction of precipitation in flood season in Haihe River Basin [J]. Water Resources Planning and Design, 2017(10):60-63+86.

25. GP. Cen, J. Shen, RS. Fan. Study on urban design storm pattern [J]. Advances in Water Science, 1998(01):42-47.

26. DZ. Xia, XN. Zhang, YH. Fang, et al. Rainfall intensity ratio control based on rainfall spray control system $[\mathrm{J}]$. Research and Exploration in Laboratory, 2010, 29(09):4-7. 